\title{
Anomalies in carbon concentration determinations from nanostructured bainite
}

\author{
H. K. D. H. Bhadeshia ${ }^{a}$ \\ ${ }^{a}$ Materials Science and Metallurgy, University of Cambridge, U. K.
}

\begin{abstract}
There are large discrepancies in the measured concentrations of carbon in the ferrite and austenite within nanostructured bainite and carbide-free bainitic steels in general. The concentrations are usually measured on the basis of lattice parameters determined using X-ray diffraction, lattice imaging in transmission microscopy, or using the atom probe technique, i.e., time-of-flight mass spectroscopy. We examine here a number of difficulties with these methods and assess the role of defects, crystal symmetry and the heterogeneous distribution of carbon in interpreting the experimental data. Issues where experimental and theoretical work is needed are identified.
\end{abstract}

Keywords: lattice parameters, carbon, dislocations, density, bainite, retained austenite

\section{Introduction}

The carbon concentration of austenite and ferrite in steels is determined routinely by measuring the lattice parameters using X-ray diffraction, and then using a variety of empirical equations [1-8] that express the parameters as a function of the carbon concentration. There is some confidence in these equations since for austenite the parameters are from equilibrium microstructures [1, 2], and because there is good agreement between atomistic modelling and the measured parameters of martensite in Fe-C systems [9]. However, there are many examples in the published literature on mixtures of bainitic ferrite $\left(\alpha_{b}\right)$ and austenite $(\gamma)$ where the concentrations determined 
in this way often do not satisfy a mass balance, leading to the inequality:

$$
V_{\gamma} x_{\gamma}+\left(1-V_{\gamma}\right) x_{\alpha_{b}} \neq \bar{x}
$$

where the small density difference between the $\alpha_{b}$ and $\gamma$ is neglected, $\bar{x}$ is the average concentration of carbon in the steel; $x_{\alpha_{b}}$ and $x_{\gamma}$ are the corresponding concentrations in austenite and ferrite respectively. $V_{\gamma}$ is the volume fraction of austenite so it follows that for a two-phase microstructure, $1-V_{\gamma}$ is the ferrite volume fraction. In fact, the term on the left-hand side of the equation is often much less than $\bar{x}$. For example, it is reported [10] that with $V_{\gamma}=0.29 \pm 0.02, x_{\alpha_{b}}=0.66 \pm 0.24 \mathrm{at} \%, x_{\gamma}=8.3 \pm 2.7$ at $\%$ and $\bar{x}=4.34 \mathrm{at} \%$, about 1.5 at\% of carbon is unaccounted for if equation 1 is applied. Taking the most pessimistic values of the error bars in the measurements, the range of concentration unaccounted for is $0.31-2.5 \mathrm{at} \%$. These measurements are atom-probe data on nanostructured bainite, a two-phase mixture of austenite and bainitic ferrite. There may be difficulties with the atom probe technique for carbon, but the uncertainties reported $[11,12]$ in fact lead to an overestimation of the carbon concentration and hence do not resolve the difficulties highlighted here. Whilst this aspect is not the focus of the current paper, it is noted that there exist dedicated studies in the literature that address the issues surrounding detection and analysis of carbon in steel using both voltage-pulsed and laser-pulsed atom probe techniques [11, 13-15].

Other data based on X-ray diffraction show the same level of discrepancy, ranging from $0.93-1.61$ at\% of carbon $[16,17]$ and the problem is not limited to the references quoted here.

The purpose of this note is to understand the origin of these discrepancies. The focus will be on nanostructured bainite, usually formed by phase transformation at about $200^{\circ} \mathrm{C}$, where the most comprehensive data exist.*

*When bainite is formed by partial isothermal transformation and then cooled to ambient temperature, some of the residual austenite may transform into martensite. In the present work, the only data analysed are those consisting of two-phase mixtures of bainitic ferrite and retained austenite. We note also that very small particles of carbides have been detected using the atom probe [18] but they are not apparent in X-ray diffraction patterns, and not seen using transmission electron microscopy, so they are likely to represent an insignificant phase fraction. 


\section{Materials Science and Technology 31 (2015) 758-763}

\section{Density change due to dislocations}

It is now well-established that bainitic ferrite is supersaturated with carbon when the concentration is assessed with respect to the conventional $\alpha_{b} / \gamma$ phase equilibrium, and that some of the excess carbon is trapped at dislocations $\left(x_{\alpha_{b}}^{\rho}\right)$ and other defects [17-26]. However, experiments where the distribution of carbon is studied in detail show beyond doubt that a substantial concentration is present in solid solution $\left(x_{\alpha_{b}}^{s s}\right)$ in nanostructured bainite $[10,27,28]$ and in spite of prolonged heat treatment where carbon is mobile $[29,30]$.

Cottrell and Bilby [31] proposed that an estimate of the number of impurity atoms required to saturate a dislocation can be made by equating the volume changes due to the impurity atoms and that due to the dislocation strain field. Although the estimate is not strictly accurate due to core effects [32], it is argued here that if such cancellation occurs then $x_{\alpha_{b}}^{\rho}$ does not contribute to lattice expansion; only the carbon $x_{\alpha_{b}}^{s s}$ in solid solution would lead to lattice expansion and hence be measurable by X-ray diffraction that relies on lattice parameter measurements. Trapped carbon is present in regions of the lattice that already are dilated due to the strain field of the defect [33], thus contributing much less to expansion than when placed in the perfect lattice.

The concentration $x_{\alpha_{b}}^{\rho}$ is calculated approximately by considering the change in density due to the introduction of dislocations into a crystal. It is important to note that although there is a decrease in density, the dislocations do not cause a change in the lattice parameter. This volume expansion caused by dislocations is given by [33]:

$$
\Gamma \ln \left\{R / r_{0}\right\}=\frac{\delta v b}{\Omega}
$$

where $\delta v$ is the volume expansion per unit length of dislocation, and $\Omega=$ $4 b^{3} / 3^{3 / 2}$ is the atomic volume in a body-centred cubic crystal. It follows that $\Gamma \ln \left\{R / r_{0}\right\}$ is the volume change per atomic volume $\Omega$, due to a dislocation of length equal to the magnitude of the Burgers vector $b, r_{0}$ is the dislocation core radius, and $R$ is outer radius, the effective distance to which the strain field of the dislocation extends. For a body-centred cubic crystal of iron, $\Gamma$ has been derived to be in the range $0.3-0.38$ depending on the screw or edge character of the dislocation [33]. 
The relationship between the dislocation density $\rho$ and $R$ depends on how effectively the dislocation strain fields are screened by interactions. Since the dislocations in bainite are not in ordered arrays, the screening should be small. It is assumed therefore that $R$ will be equal to the mean lineal intercept within a bainite platelet. Given that the true thickness of nanostructured bainite is $20-40 \mathrm{~nm}$ [34], and since the mean lineal intercept for a plate shape is twice the true thickness [35], $R=40-80 \mathrm{~nm}$.

When carbon is inserted into otherwise perfect ferrite, the cubic cell with lattice parameter $a_{c}$ changes into a tetragonal cell with parameters $a_{t}$ and $c_{t}$ as a consequence of the Bain deformation. The degree of tetragonality is a function of the concentration of carbon $\left(x_{\alpha_{b}}^{s s}\right)$ [36-38]. The volume change caused by the insertion of a single carbon atom into a unit cell of body-centred cubic iron has been calculated to be $\Delta V_{C}=0.78 \times 10^{-29} \mathrm{~m}^{3}[31]$.

If it is possible to fill the total excess-space created by introducing dislocations with that needed to accommodate carbon atoms, then the number of carbon atoms able to enter a unit volume of ferrite without altering its lattice parameter is given by:

$$
N_{V}^{C}=\frac{\Omega \Gamma \ln \left\{R / r_{0}\right\}}{\Delta V_{C}} \times \frac{\rho}{b}
$$

with the weight percent of carbon accommodated without altering the lattice parameter given by

$$
w_{C} \approx \frac{12.011 \times N_{V}^{C}}{55.847 / \Omega} \times 100
$$

where the atomic weights of carbon and iron are 12.011 and $55.857 \mathrm{~g} \mathrm{~mol}^{-1}$ respectively. Table 1 summarises the data for the reported dislocation density [39].

Table 1: Calculations of carbon concentration that in the presence of dislocations does not lead to a change in lattice parameter.

\begin{tabular}{cccc}
\hline$\rho / \mathrm{m}^{-2}$ & $R / \mathrm{nm}$ & $x_{\alpha_{b}}^{\rho} /$ at $\%$ & $x_{\alpha_{b}}^{\rho} / \mathrm{wt} \%$ \\
\hline $6.4 \times 10^{15}$ & 40 & 0.089 & 0.019 \\
$6.4 \times 10^{15}$ & 80 & 0.101 & 0.022 \\
\hline
\end{tabular}




\section{X-rays and segregated carbon}

Modern atom probe studies of nanostructured bainite have shown carbon atoms segregated to dislocations, in a cylinder of radius $\approx 1.25 \mathrm{~nm}$ about the dislocation line at the centre [18]. Suppose that the change in density due to dislocations is neglected, and that in the first instance, the concentration of carbon in the enriched cylinder is rather small but equal to $x_{\alpha_{b}}^{s s}(0.16 \mathrm{wt} \%$ or 0.75 at\%). The local lattice parameter would be expanded by $4.8 \times 10^{-4} \mathrm{~nm}$ [38]. The volume fraction of such a cylinder, given a dislocation density of $6.4 \times 10^{15} \mathrm{~m}^{-2}[39]$, would be $V_{\phi}=0.031$.

Suppose that the segregated dislocations are treated as a separate phase $\phi$ with an body-centred cubic crystal structure but the expanded lattice parameter and volume fraction $V_{\phi}$ in a matrix of ferrite $\alpha_{b}$, then the simulated $\mathrm{X}$-ray diffraction patterns from the phase mixture are illustrated in Fig. 1. Since all published X-ray diffraction patterns treat the ferrite as a compositionally homogeneous phase with a single lattice parameter, the carbon that is located at dislocations is basically not detected because that would require a much more detailed analysis of peak shape. The information would for all those experiments be hidden in the fitting error associated with the Reitveld refinement.

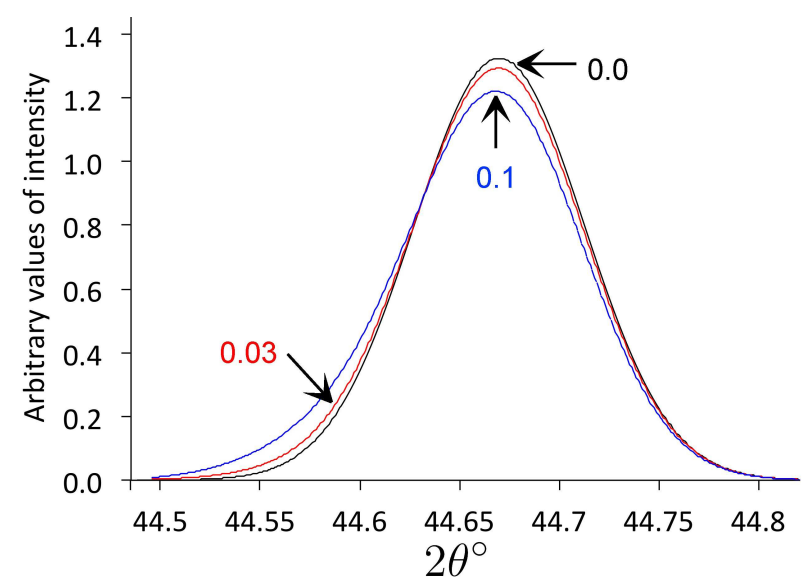

Figure 1: Simulated X-ray diffraction $\{110\}$ patterns from a mixture of $\alpha_{b}$ and $\phi$ phases, with different $V_{\phi}$ values marked on the plot. The wavelength is $0.1541 \mathrm{~nm}$, $a_{\alpha_{b}}=0.28664 \mathrm{~nm}, a_{\phi}=0.28712 \mathrm{~nm}$, where $a$ is the lattice parameter of the phase identified by the subscript. 


\section{Materials Science and Technology 31 (2015) 758-763}

Evidence from atom probe experiments $[18,40]$ suggests that the average concentration of carbon in a Cottrell atmosphere is about 7.4-8 at\%, i.e., an order of magnitude greater than used in the calculations illustrated in Fig. 1. Such a large concentration of carbon would lead to a major expansion of the lattice parameter in the locality, to some $0.291 \mathrm{~nm}$, although some of this expansion would be compensated by the original strain field of the dislocation. But in the absence of such compensation, the diffraction pattern expected would appear as in Fig. 2, with a small secondary peak corresponding to $\{110\}_{\phi}$ within $<1^{\circ} 2 \theta$ of the main reflection. Such a secondary peak would be difficult to resolve experimentally because a typical $\{110\}_{\alpha_{b}}$ peak is 7$8^{\circ} 2 \theta$ in width [41] so that any low-intensity peak located within $\pm 4^{\circ}$ of the exact Bragg condition would become insignificant. The problem becomes worse when retained austenite is present since the $\{111\}_{\gamma}$ peak is in close proximity to the $\{110\}_{\alpha_{b}}$ reflection, Fig. 2. This large broadening of the experimental peak is due to the nanostructure (crystallite size broadening) and heterogeneous strains due to defects.

Not all the dislocations may carry Cottrell atmospheres; only those with the saturated atmospheres can be identified using the atom probe technique that relies on composition mapping. Free dislocations can of course be imaged in a field ion microscope rather than identified by composition mapping.

\section{X-rays and tetragonality}

Synchrotron X-ray analysis of nanostructured bainite transformed at $200^{\circ} \mathrm{C}$ indicated the carbon concentration in bainitic ferrite to be $0.16 \mathrm{wt} \%$, determined from the $c / a$ ratio of a tetragonal unit cell [41]. This is far greater than expected from paraequilibrium, but consistent with atom-probe data $[10,27,28]$. On the other hand, indexing the structure as body-centred cubic ferrite, with a lower degree of fit in the Reitveld analysis, gave a lattice parameter of $0.286343 \pm 0.000009 \mathrm{~nm}$, whereas that of pure iron at room temperature is $0.28664 \mathrm{~nm}[5]$; taken at face value, this would give a zero carbon content in the ferrite, clearly inconsistent with recorded values of $x_{\alpha_{b}}^{s s}$.

\section{X-rays from dislocations with segregated impurities}

X-ray line broadening is often used to characterise dislocations, including during investigations of nanostructured bainite [17]. The diffraction contrast 


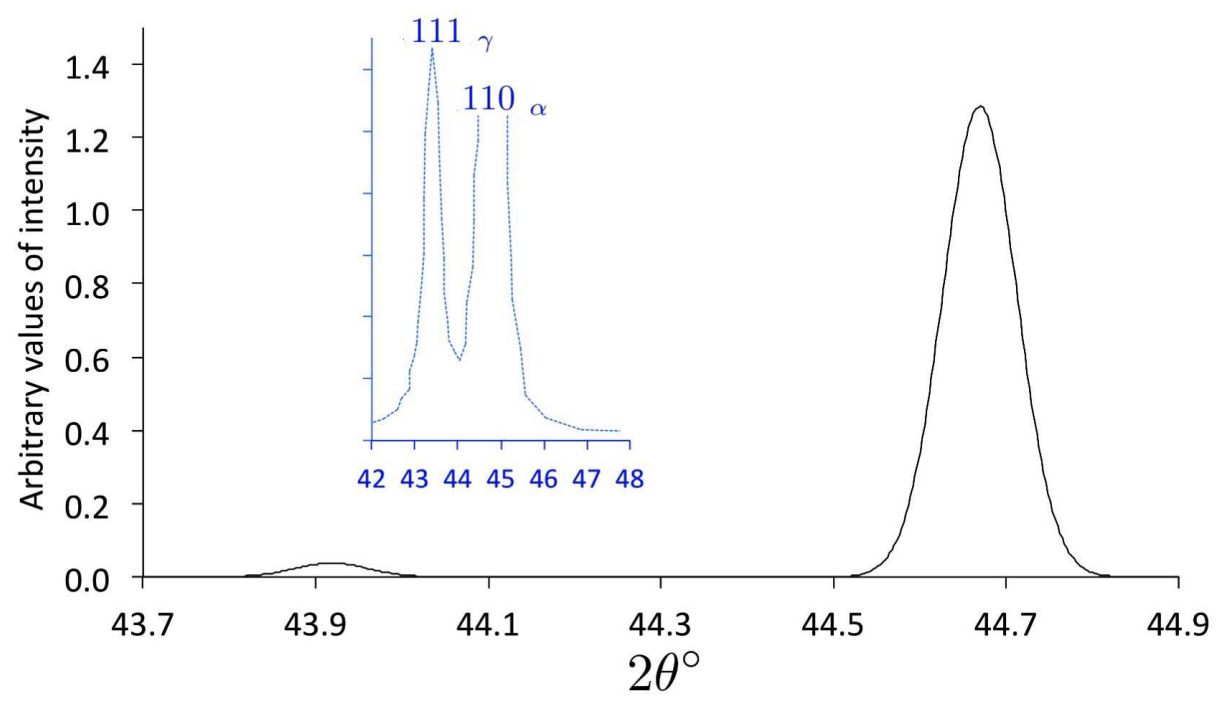

Figure 2: Simulated X-ray diffraction $\{110\}$ pattern from a mixture of $\alpha_{b}$ and $\phi$ phases, with $V_{\phi}=0.03$. The wavelength is $0.1541 \mathrm{~nm}, a_{\alpha_{b}}=0.28664 \mathrm{~nm}, a_{\phi}=0.291 \mathrm{~nm}$. The inset shows part of an actual pattern from nanostructured bainite in order to illustrate the real breadth of measured X-ray peaks [41].

used in such analyses relies entirely on the heterogeneous strains fields due to dislocations. It is these strain fields that attract the carbon atoms; it follows that their segregation must reduce the potency of the dislocations as strain centres. This is why, for example, the formation of etch-pits due to dislocations intersecting the surface of lithium fluoride crystals is reduced when the crystal contains impurities that segregate to dislocations [42].

There does not seem to be any theory that accounts for the deduction of dislocation density in circumstances where their strain fields have been compromised by the formation of Cottrell atmospheres. The net effect should be to underestimate the dislocation density.

\section{Interfaces}

Nanostructured bainite contains a very large surface area of $\alpha_{b} / \gamma$ interfaces per unit volume, $S_{V}=10^{8} \mathrm{~m}^{-1}$. This is comparable to what is achieved by mechanical milling and other modes of severe plastic deformation [43]. Any carbon segregated to these interfaces could account for some of 
the "missing" carbon. However, atomic resolution experiments have demonstrated that there is no such segregation, the carbon concentration following a step profile on traversing from ferrite to austenite as illustrated in Fig. 3. This could be a consequence of the high degree of coherence associated with the displacive mechanism of transformation.

Fig. 3 also shows that the concentration profile at the interface extends over a distance of about $8 \mathrm{~nm}$, but this is because these particular measurements were not optimised for interfacial width measurement, together with some instrumental issues [44]. The latter include small movements of atoms as they field evaporate, differences in the evaporation fields of adjacent phases leading to magnification and trajectory aberrations,larger atoms being pushed out preferentially just prior to evaporation; in addition, surface roughness may contribute to the spread. High-resolution transmission electron microscopy on bainite formed in $\mathrm{Fe}-2 \mathrm{Si}-1.4 \mathrm{C}$ wt\% alloy indicates that the interface is in fact sharp, less than $1 \mathrm{~nm}$ in width [45-47]. The thickness and interfacial concentration assumed in calculations to be presented later are taken to be $1 \mathrm{~nm}$ and 4 at\% respectively.

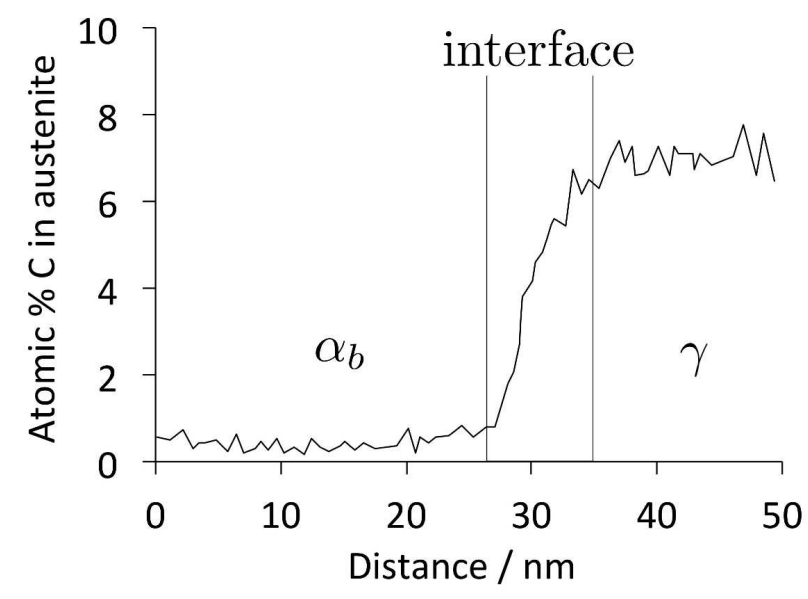

Figure 3: Concentration profile across an $\alpha_{b} / \gamma$ interface in nanostructured bainite. Adapted from [18], with permission from Elsevier.

\section{Atom probe data}

Depending on the energy of X-rays, the number of atoms that is probed is between $10^{4}$ and $10^{13}$, which is greater than in a typical atom-probe analysis where one to tens of million atoms are collected for time-of-flight mass 


\section{Materials Science and Technology 31 (2015) 758-763}

spectroscopy. The carbon concentration of austenite following isothermal transformation to the limiting fraction of bainitic ferrite is not constant, with smaller regions of austenite containing greater concentrations of carbon $[19,20,28,48-52]$. This is because although the growth of bainite terminates when $x_{\gamma} \approx x_{T_{0}}$, films of austenite between the bainite plates can continue to accumulate carbon to a concentration $x_{A e 3^{\prime}}[19,20]$. Here $x_{\gamma}$ is the concentration of carbon in the austenite, $x_{T_{0}}$ is that in austenite beyond which diffusionless transformation becomes thermodynamically impossible, and $x_{A e 3^{\prime}}$ is the paraequilibrium concentration of austenite that is in contact with bainitic ferrite.

What then are the implications of attempting to correlate X-ray data and those from the atom probe, and in using a number of atom probe measurements to assess the average concentration in austenite or in ferrite? Obviously, the X-ray method has to be better in assessing averaged concentrations in a heterogeneous sample. Indeed, in many cases, at least two lattice parameters are observed due to the heterogeneous distribution of carbon in films and blocks of austenite $[49,53-55]$. When the austenite is not stable, two different martensite-start temperatures have been noted [56].

A simple model was created to treat the problem of atom-probe sampling when the austenite composition is not uniform over length scales well beyond the sample sizes possible with the technique. The lowest concentration was set for the largest austenite regions, at $x_{T_{0}}$, and the highest at 1.5 times this value. Two forms of variations were assumed as a function of the size of the austenite, the first linear, and the second exponential (Fig. 4a). The exponential decay accounts for the fact that the accumulation of carbon beyond $x_{T_{0}}$ is likely to be important only for isolated thin films of austenite rather than the so-called blocky regions; this tendency is consistent with a trend observed from atom-probe data [57]. Thus, for the purposes of modelling, the austenite was effectively divided into one thousand particles, each with a different uniform concentration, Fig. 4a.

Average values $\left(\bar{x}_{\gamma}\right)$ of atom-probe determined concentrations are reported in the literature, calculated from less than 10 independent experiments on a given sample. Therefore, ten of these austenite particles in the model were picked at random and an average concentration calculated, $\bar{x}_{\gamma}=\frac{1}{10} \times \sum_{i=1}^{10} x_{\gamma_{i}}$, where $i$ represents a particle in the set of ten particles. This procedure was repeated 100 times to obtain the distribution of $\bar{x}_{\gamma}$, as 
shown in Fig. 4c. It is clear that the value of $\bar{x}_{\gamma}$ obtained from ten atom probe experiments will be dependent on sampling ${ }^{\dagger}$.

An additional analysis was conducted where the exponential variation (Fig. 4a) was truncated to exclude half of the largest austenite regions. This is because a typical atom-probe tip is about $20 \mathrm{~nm}$ in thickness, and many of the reported data show films enclosed in such tips. Thus, there may be a bias towards sampling only the small regions. In cases where larger regions of austenite are sampled in the tip, the maximum extent of the austenite in the direction of the thickness of the tip is not known. The effect of the biased sampling of thin films of austenite is predicted to be a larger averaged concentration (Fig. 4c).

(a)
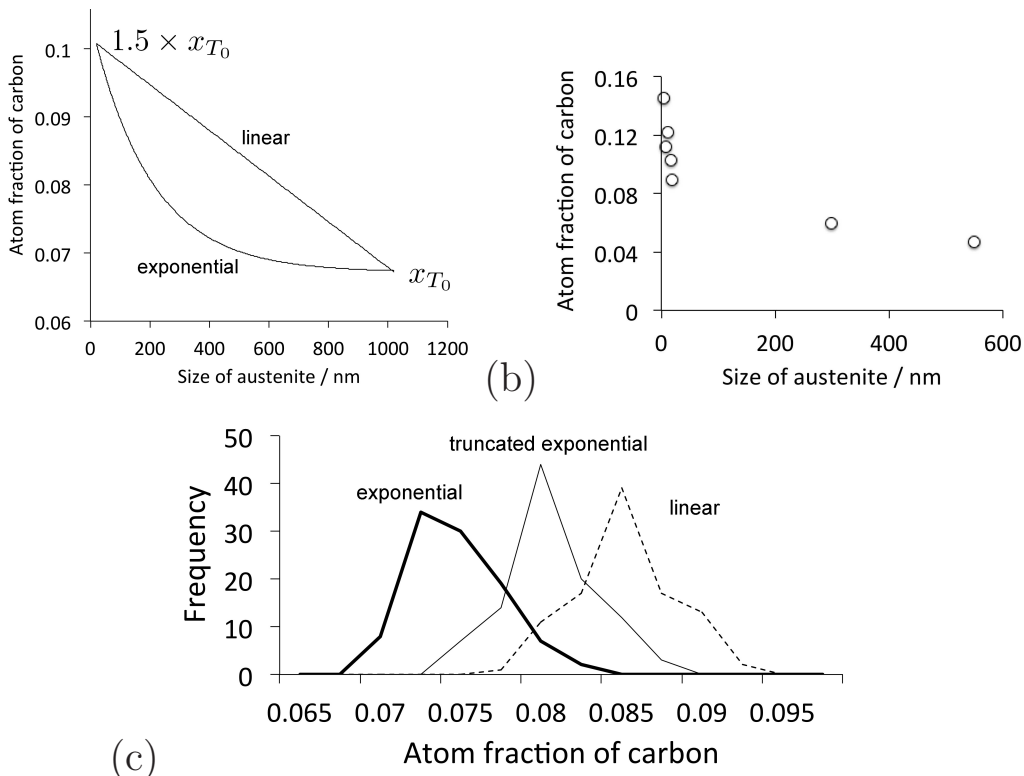

Figure 4: (a) Test distributions of carbon content in austenite as a function of the size of the austenite region. (b) Experimental data from [57] replotted on a linear scale. (c) Distributions of the mean of ten atom-probe data sampled from specimens containing the concentration variations illustrated in (a). The truncated distribution is based on the assumption that most atom probe data do not relate to the largest fifty percent of austenite regions.

$\dagger$ This variation is separate from the statistical error due to the number of atoms involved in each experiment, instrumental issues etc. It is solely due to the heterogeneous distribution of carbon in the austenite. 


\section{Discussion and Conclusions}

It was explained in the introduction that there are discrepancies in achieving a mass balance for carbon, when the concentration of the latter is determined using either X-ray measurements of concentration-dependent lattice parameters, or using the more direct technique of atom-probe analysis. The stated uncertainties in the individual measurements would indicate that the deficit for nanostructured bainite could be in the range $0.31-2.5$ at $\%$. When deriving averaged values there will be additional uncertainties in the atom probe data, related to the non-uniform distribution of carbon in the austenite; this particular issue has not been considered when averaged values are derived from atom-probe data on nanostructured bainite. Table 2 indicates that the presence of carbon at defects could in principle explain up to 0.7 at\% of the deficit when applying equation 1 .

Table 2: Estimation of carbon located at defects

\begin{tabular}{lccc}
\hline \multicolumn{4}{c}{ Table 2: Estimation of carbon located at defects. } \\
\hline Defect & Density & Volume fraction & $V x$ at\% \\
\hline Carbon atoms not contributing to expansion & & & 0.10 \\
Dislocations with Cottrell atmosphere of 8 at\% & $6.4 \times 10^{15} \mathrm{~m}^{-2}$ & 0.031 & 0.25 \\
$\alpha_{b} / \gamma$ interfaces, 1 nm thick, containing 4 at\% C & $10^{8} \mathrm{~m}^{-1}$ & 0.1 & 0.32 \\
\hline
\end{tabular}

However, the work presented here does not entirely solve the problem of determining the compositions of two-phase mixtures of bainitic ferrite and austenite. This is because there are a number of critical experiments and theoretical analyses necessary in order to make progress. These include:

(i) a theoretical treatment of X-ray diffraction from dislocations saturated with Cottrell atmospheres, bearing in mind that solute segregation of this kind leads to at least a partial compensation of the strain field of the dislocation.

(ii) An assessment as to whether fitting errors during Reitveld refinement of X-ray diffraction patterns are due to the assumption that the ferrite lattice has cubic symmetry.

(iii) Clarity on whether the majority of dislocations in nanostructured bainite are decorated with Cottrell atmospheres. 
(iv) An understanding of why carbon does not seem to segregate to $\alpha_{b} / \gamma$ interfaces, and further atom probe investigations to optimise the experimental conditions so that narrower composition profiles are produced, consistent with transmission electron microscopy of the extent of the transition region between $\alpha_{b}$ and $\gamma$.

One aspect not discussed here is the state of residual, microscopic typeIII stresses [58, 59] within the specimens of nanostructured bainite. Such stresses are inevitable given the large shape deformation accompanying the formation of such bainite [60] and should affect the determination of the carbon concentration as a function of the lattice parameters. A detailed Eshelby analysis of the role of transformation strains in determining the carbon concentration using lattice parameter equations has been reported in the context of carbide-free bainite [61]. This indicates small elastic strains in the austenite of $\varepsilon_{11}=\varepsilon_{22}=3.65 \times 10^{-5}, \varepsilon_{33}=7.3 \times 10^{-5}$, so that the error in deducing the carbon concentration of the austenite would be of the order of just $0.01 \mathrm{wt} \%$ [61]. This does not exclude the role of macroscopic residual stresses in general, but the heat treatment involved in the production of nanostructured bainite should exclude these given that the transformation occurs over very long periods of time whilst the specimen is at a homogeneous temperature [62]. 


\section{References}

1. N. Ridley, H. Stuart, and L. Zwell: 'Lattice parameters of Fe-C austenites at room temperature', Trans. Met. Soc. AIME, 1969, 245, 18341836 .

2. D. J. Dyson, and B. Holmes: 'Effect of alloying additions on the lattice parameter austenite', Journal of the Iron and Steel Institute, 1970, 208, 469-474.

3. L. Cheng, A. Böttger, T. H. de Keijser, and E. J. Mittemeijer: 'Lattice parameters of iron-carbon and iron-nitrogen martensites and austenites', Scripta Metallurgica and Materialia, 1990, 24, 509-514.

4. M. Onink, C. M. Brakman, F. D. Tichelaar, E. J. Mittemeijer, and S. van der Zwaag: 'Lattice parameters of austenite and ferrite in $\mathrm{Fe}$ C alloys as function of carbon concentration and temperature', Scripta Metallurgica and Materialia, 1993, 28, 1011-1016.

5. S. J. Lee, and Y. K. Lee: 'Quantitative analyses of ferrite lattice parameter and solute $\mathrm{Nb}$ content in low carbon microalloyed steels', Scripta Materialia, 2005, 52, 973-976.

6. C. P. Scott, and J. Drillet: 'A study of the carbon distribution in retained austenite', Scripta Materialia, 2007, 56, 489-492.

7. T. S. Hummelshoj, T. L. Christiansen, and M. A. Somers: 'Lattice expansion of carbon-stabilized expanded austenite', Scripta Materialia, 2010, 63, 761-763.

8. C. Zhao, W. Q. Cao, C. Zhang, Z. G. Yang, H. Dong, and Y. Q. Weng: 'Effect of annealing temperature and time on microstructure evolution of 0.2C-5Mn steel during intercritical annealing process', Materials Science and Technology, 2014, 30, 791-799.

9. C. S. Becquart, J. M. Raulot, G. Bencteux, C. Domain, M. Perez, S. Garruchet, and H. Nguyen: 'Atomistic modeling of an Fe system with a small concentration of C', Computational Materials Science, 2007, 40, 119-129. 
10. F. G. Caballero, M. K. Miller, C. Garcia-Mateo, and J. Cornide: 'New experimental evidence of the diffusionless transformation nature of bainite', Journal of Alloys and Compounds, 2013, 577, S626-S630.

11. J. Takahashi, K. Kawakami, and Y. Kobayashi: 'Quantitative analysis of carbon content in cementite in steel by atom probe tomography', Ultramicroscopy, 2011, 111, 1233-1238.

12. G. Miyamoto, K. Shino, and T. Furuhara: 'Quantitative measurement of carbon content in $\mathrm{Fe}-\mathrm{C}$ binary alloys by atom probe tomography', Scripta Materialia, 2012, 67, 999-1002.

13. W. Sha, L. Chang, G. D. W. Smith, L. Cheng, and E. J. Mittemeijer: 'Some aspects of atom-probe analysis of Fe-C and F- N systems', Surface Science, 1992, 266, 416-423.

14. R. K. W. Marceau, P. Choi, and D. Raabe: 'Understanding the detection of carbon in austenitic high-mn steel using atom probe tomography', Ultramicroscopy, 2013, 132, 239-247.

15. H. S. Kitaguchi, S. Lozano-Perez, and M. P. Moody: 'Quantitative analysis of carbon in cementite using pulsed laser atom probe', Ultramicroscopy, 2014, 147, 51-60.

16. C. Garcia-Mateo, F. G. Caballero, and H. K. D. H. Bhadeshia: 'Development of hard bainite', ISIJ International, 2003, 43, 1238-1243.

17. C. Garcia-Mateo, M. Peet, F. G. Caballero, and H. K. D. H. Bhadeshia: 'Tempering of a hard mixture of bainitic ferrite and austenite', Materials Science and Technology, 2004, 20, 814-818.

18. F. G. Caballero, M. K. Miller, S. S. Babu, and C. Garcia-Mateo: 'Atomic scale observations of bainite transformation in a high carbon high silicon steel', Acta Materialia, 2007, 55, 381-390.

19. H. K. D. H. Bhadeshia, and A. R. Waugh: 'Bainite: An atom probe study of the incomplete reaction phenomenon', Acta Metallurgica, 1982, 30, $775-784$.

20. H. K. D. H. Bhadeshia, and A. R. Waugh: 'An atom-probe study of bainite', In: H. I. Aaronson, D. E. Laughlin, R. F. Sekerka, and 
C. M. Wayman, eds. Solid-Solid Phase Transformations. Warrendale, Pennsylvania, USA: TMS-AIME, 1982:993-998.

21. I. Stark, G. D. W. Smith, and H. K. D. H. Bhadeshia: 'The element distribution associated with the incomplete reaction phenomenon in steels: an atom probe study', In: G. E. Lorimer, ed. Phase Transformations '87. London, U.K.: Institute of Metals, 1988:211-215.

22. I. Stark, G. D. W. Smith, and H. K. D. H. Bhadeshia: 'Distribution of substitutional alloying elements during the bainite transformation', Metallurgical transactions A, 1990, 21, 837-844.

23. M. Peet, S. S. Babu, M. K. Miller, and H. K. D. H. Bhadeshia: 'Three-dimensional atom probe analysis of carbon distribution in lowtemperature bainite', Scripta Materialia, 2004, 50, 1277-1281.

24. E. V. Pereloma, E. V. Timokhina, M. K. Miller, and P. D. Hodgson: 'Three-dimensional atom probe analysis of solute distribution in thermomechanically processed TRIP steels', Acta Materialia, 2007, 55, 25872598.

25. F. G. Caballero, M. K. Miller, A. J. Clarke, and C. Garcia-Mateo: 'Examination of carbon partitioning into austenite during tempering of bainite', Scripta Materialia, 2010, 63, 442-445.

26. I. B. Timokhina, X. Y. Xiong, H. Beladi, S. Mukherjee, and P. D. Hodgson: 'Three-dimensional atomic scale analysis of microstructures formed in high strength steels', Materials Science and Technology, 2011, 27, 739-741.

27. F. G. Caballero, M. K. Miller, C. Garcia-Mateo, J. Cornide, and M. J. Santofimia: 'Temperature dependence of carbon supersaturation of ferrite in bainitic steels', Scripta Materialia, 2012, 67, 846-849.

28. E. Pereloma, H. Beladi, L. Zhang, and I. Timokhina: 'Understanding the behavior of advanced high-strength steels using atom probe tomography', Metallurgical \& Materials Transactions A, 2012, 43, 3958-3971.

29. J. H. Jang, H. K. D. H. Bhadeshia, and D. W. Suh: 'Solubility of carbon in tetragonal ferrite in equilibrium with austenite', Scripta Materialia, 2012, 68, 195-198. 
30. H. K. D. H. Bhadeshia: 'Carbon in cubic and tetragonal ferrite', Philosophical Magazine, 2013, 93, 3714-3715.

31. A. H. Cottrell, and B. A. Bilby: 'Dislocation theory of yielding and strain ageing of iron', Proc. Physics Society A, 1949, 62, 49-62.

32. R. Thomson: 'The nonsaturability of the strain field of a dislocation by point imperfections', Acta Metallurgica, 1958, 6, 23-28.

33. A. Seegar, and P. Haasen: 'Density changes of crystals containing dislocations', Philosophical Magazine, 1958, 3, 470-475.

34. C. Garcia-Mateo, F. G. Caballero, and H. K. D. H. Bhadeshia: 'Mechanical properties of low-temperature bainite', Materials Science Forum, 2005, 500-501, 495-502.

35. L. C. Chang, and H. K. D. H. Bhadeshia: 'Austenite films in bainitic microstructures', Materials Science and Technology, 1995, , 874-881.

36. K. Honda, and S. Saito: 'On the formation of spheroidal cementite', Journal of the Iron and Steel Institute, 1920, 102, 261-267.

37. W. C. Leslie: The Physical Metallurgy of Steels: McGraw Hill, New York, 1982.

38. H. K. D. H. Bhadeshia, S. A. David, J. M. Vitek, and R. W. Reed: 'Stress induced transformation to bainite in a Fe-Cr-Mo-C pressure vessel steel', Materials Science and Technology, 1991, 7, 686-698.

39. H. Y. Li, and X. J. Jin: 'Determination of dislocation density in nanostructured bainitic steels', Journal of Shanghai Jiaotong University, 2010, 44, 613-615.

40. J. Wilde, A. Cerezo, and G. D. W. Smith: 'Three-dimensional atomicscale mapping of a Cottrell atmosphere around a dislocation in iron', Acta Materialia, 2000, 43, 39-48.

41. C. N. Hulme-Smith, I. Lonardelli, A. C. Dippel, and H. K. D. H. Bhadeshia: 'Experimental evidence for non-cubic bainitic ferrite', Scripta Materialia, 2013, 69, 409-412. 
42. J. J. Gilman, W. G. Johnston, and G. W. Sears: 'Dislocation etch pit formation in lithium fluoride', Journal of Applied Physics, 1958, 29, $747-754$.

43. H. K. D. H. Bhadeshia: 'The first bulk nanostructured metal', Science and Technology of Advanced Materials, 2013, 14, 014202.

44. F. G. Caballero, and M. K. Miller: 'Private communication', 2014: Interfacial width in atom probe tomography.

45. S. Kajiwara, K. Ogawa, T. Kikuchi, H. Okamoto, and M. Oka: 'High resolution electron microscopy studies of the austenite-martensite and austenite-bainite interfaces in Fe-based alloys', In: T. M. M. Koiwa, K. Otsuka:, ed. Solid-Solid Phase Transformations '99 (JIMIC-3). Tokyo, Japan: Japan Institute of Metals, 1999:969-972.

46. S. Kajiwara: 'HREM study on the ledge structures, transient lattices and dislocation structures at the austenite-martensite and austenitebainite interfaces in fe-based alloys', Journal de Physique IV, 2003, 112, 61-83.

47. K. Ogawa, and S. Kajiwara: 'Basic difference between martensitic and bainitic transformations revealed by high-resolution electron microscopy', Materials Science \&f Engineering A, 2006, 438-440, 90-94.

48. P. G. Self, H. K. D. H. Bhadeshia, and W. M. Stobbs: 'Lattice spacings from lattice fringes', Ultramicroscopy, 1981, 6, 29-40.

49. H. J. Stone, M. J. Peet, H. K. D. H. Bhadeshia, P. J. Withers, S. S. Babu, and E. D. Specht: 'Synchrotron X-ray studies of austenite and bainitic ferrite', Proceedings of the Royal Society A, 2008, 464, 1009-1027.

50. C. Garcia-Mateo, F. G. Caballero, M. K. Miller, and J. A. Jimenez: 'On measurement of carbon content in retained austenite in a nanostructured bainitic steel', Journal of Materials Science, 2012, 47, 1004-1010.

51. F. G. Caballero, M. K. Miller, and C. Garcia-Mateo: 'Tracking solute atoms during bainite reaction in a nanocrystalline steel', Materials Science and Technology, 2010, 26, 889-898. 


\section{Materials Science and Technology 31 (2015) 758-763}

52. F. Caballero, M. Miller, and C. Garcia-Mateo: 'Carbon supersaturation of ferrite in a nanocrystalline bainitic steel', Acta Materialia, 2010, 59, $2338-2343$.

53. S. J. Matas, and R. F. Hehemann: 'The structure of bainite in hypoeutectoid steels', TMS-AIME, 1961, 221, 179-185.

54. Y. N. Taran, K. I. Uzlov, and A. Y. Kutsov: 'Bainite reaction kinetics in austempered ductile iron', Journal de Physique IV (Colloque), 1997, 7, C5-429-434.

55. A. Kutsov, Y. Taran, K. Uzlov, A. Krimmel, and M. Evsyukov: 'Formation of bainite in ductile iron', Materials Science \&f Engineering A, 1999, 273-275, 480-484.

56. Z. Lawrynowicz: 'Carbon partitioning during bainite transformation in low alloy steels', Materials Science and Technology, 2002, 18, 1322-1324.

57. F. G. Caballero, M. K. Miller, and C. G. Mateo: 'Opening previously impossible avenues for phase transformation in innovative steels by atom probe tomography', Materials Science and Technology, 2014, 30, 10341039.

58. P. J. Withers, and H. K. D. H. Bhadeshia: 'Residual stress part 1 measurement techniques', Materials Science and Technology, 2001, 17, $355-365$.

59. P. J. Withers, and H. K. D. H. Bhadeshia: 'Residual stress part 2 nature and origins', Materials Science and Technology, 2001, 17, 366375 .

60. M. Peet, and H. K. D. H. Bhadeshia: 'Surface relief due to bainite transformation at $473 \mathrm{~K}$ ', Metallurgical \& Materials Transactions A, 2011, 42, 3344-3348.

61. D. J. Hall, H. K. D. H. Bhadeshia, and W. M. Stobbs: 'The incomplete reaction phenomenon .. TEM, atom probe', Journal de Physique IV (Colloque), 1982, 43, 449-454.

62. H. K. D. H. Bhadeshia: 'Nanostructured bainite', Proceedings of the Royal Society of London A, 2010, 466, 3-18. 